\title{
Supported glass fibers catalysts for novel multi-phase reactor design
}

\author{
L. Kiwi-Minsker*, I. Yuranov, V. Höller, A. Renken \\ Institute of Chemical Engineering, Swiss Federal Institute of Technology, CH-1015 Lausanne, Switzerland
}

\begin{abstract}
The catalytic properties of Pd and Pt supported on woven glass fabrics were explored for liquid-phase hydrogenation of benzaldehyde as a model for three-phase catalytic reaction. The catalysts demonstrated high activity and are suitable materials to be used in reactors with structured catalytic bed. The main characteristics of catalytic bed are discussed. (C) 1999 Elsevier Science Ltd. All rights reserved.
\end{abstract}

\section{Introduction}

One of the main problems in reactions performing in liquid phase over solid catalysts is an avoiding of transport limitations. If the rate of transport within the liquid to the catalytic surface determines the reaction rate, it leads to large reactor dimensions. It may also drastically influence the selectivity due to formation of undesired byproducts. The rate of transport to the catalytic surface strongly depends on the particle diameter. Therefore, small size catalytic particles are required leading to the use of suspension reactors. The minimum size of these particles is, however, limited by separation problems of the catalyst from the liquid after the reaction. Therefore, during the last decades there is a growing interest in chemical reactors with structured catalytic beds useful in three-phase reactions. The honeycomb ceramic monoliths have been suggested as one of valuable designs of the catalytic bed for liquid-phase hydrogenation, oxidation of organic/inorganic compounds and bioreactions. These reactors offer several advantages in comparison with conventional randomly packed-bed and slurry type reactors (Irandoust, Cybulski \& Moulijn, 1998). These advantages are:

(1) open macro-structure allowing high flow rates through the catalytic beds with low pressure drop

(2) improved mass transfer properties due to the shortening of the gas diffusion distance

\footnotetext{
* Corresponding author. Tel.: + 41-21-693-31-82; fax: + 41-21-6933-90.

E-mail address: lioubov.kiwi-minsker@epfl.ch (L. Kiwi-Minsker)
}

(3) high surface/volume ratio of the support, since the monolith channel walls would be usually covered by porous oxide washcoat

(4) relative ease in reactor scale-up.

The main drawbacks of monolith reactors are their high manufacturing cost and its susceptibility to thermal and mechanical stress. Moreover, the optimum performance of the monolith reactor requires uniform and stable distribution of gas and liquid over the reactor cross section, which sometimes difficult to obtain. Therefore, we have explored during this work structured catalysts made from woven glass fiber (GF) materials as catalytic supports as an alternative for structured reactor design. These catalysts combine an open macro-structure with mechanical elasticity, are easy to handle and less expensive to produce than ceramic monoliths.

The GF support is woven from long length threads consisting of a bundle of elementary filaments with the diameter of 3-15 $\mu \mathrm{m}$ (see Fig. 1a and b). Glass fiber materials in woven form can be designed with a variety of macrostructure, like tissue, gauze or 3D-blocks. It offers a large spectrum of options in the reactor design with structured catalytic beds.

The GF catalyst is made by the deposition of different active metal ions on the amorphous glass matrix. Pd and Pt supported on GF catalysts have already demonstrated high activity for the gas-solid combustion reactions (Nicholas, Shan \& Zlochower, 1976; Neyestanaki \& Lindfors, 1995; Yuranov, Kiwi Minsker, Barelko \& Renken, 1999) and for the liquid-phase hydrogenation of nitrobenzene (Barelko \& Dorohov, Private communication). Recently, we reported the results concerning the $\mathrm{CO}$ 

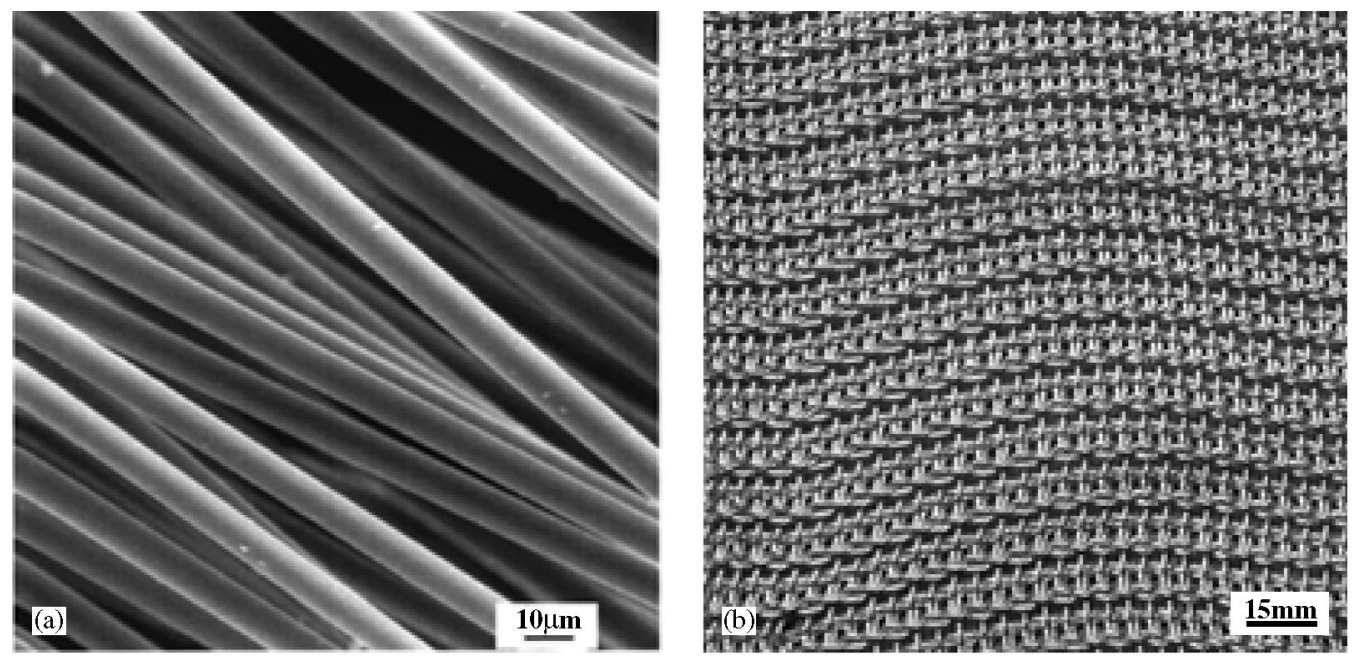

Fig. 1. (a) EM image of GF filaments; (b) the view of one catalyst layer.

oxidation at atmospheric pressure over these catalysts (Yuranov et al., 1999). The later study focused on the catalytic ignition-extinction limits and the reaction oscillatory behavior and explored the catalyst microstructure, specific surface area, porous distribution as well as surface concentration and dispersion of the active component and the influence of these parameters on the catalyst efficiency.

The present study is aimed on the development of the GF based catalysts and their application in the reactor design with structured catalytic beds for three-phase (gas-liquid-solid) reactions. The liquid-phase hydrogenation of benzaldehyde was chosen as a model of the three-phase reaction. Mostly, Raney-Nickel or precious metals are known for use in catalytic reduction. Therefore, $\mathrm{Pt}$ and $\mathrm{Pd}$ were chosen as active components. They were supported on the GF woven fabrics and their catalytic properties were evaluated as a function of specific surface area of the support, chemical composition of the glass fiber, loading of active component and catalyst pretreatment conditions.

\section{Experimental}

\subsection{Catalyst preparation and characterization}

Two types of glass fibers were used as a starting material for the preparation of the GF supports: silica glass fibers (SGF) and alumoborosilicate (widely known as E-type) glass fibers (EGF) (produced by "Steklovolokno", Polotsk, Belarus). A typical composition of these glass fibers is presented in Table 1.

The specific surface area (SSA) of the starting glass fiber materials is $2 \mathrm{~m}^{2} / \mathrm{g}$, which corresponds approximately to the geometrical specific surface of the filaments. The samples of EGF in woven form were pre-treated in
Table 1

Composition of glass fibers used as precursor for the supports

\begin{tabular}{llc}
\hline Component & $\begin{array}{l}\text { Content in } \\
\text { EGF (wt \%) }\end{array}$ & $\begin{array}{l}\text { Content in } \\
\text { SGF }(w t \%)\end{array}$ \\
\hline Silica, $\mathrm{SiO}_{2}$ & 54.0 & 93.5 \\
Boron oxide, $\mathrm{B}_{2} \mathrm{O}_{3}$ & 10.0 & - \\
Alumina, $\mathrm{Al}_{2} \mathrm{O}_{3}$ & 14.5 & $3.0-3.5$ \\
Calcia, $\mathrm{CaO}$ & 16.5 & 0.3 \\
Magnesia, $\mathrm{MgO}$ & 4.0 & Traces \\
Iron oxide, $\mathrm{Fe}_{2} \mathrm{O}_{3}$ & 0.1 & $<0.1$ \\
Sodium oxide, $\mathrm{Na}_{2} \mathrm{O}$ & 0.7 & $<1.0$ \\
Others: $\mathrm{K}_{2} \mathrm{O}, \mathrm{F}_{2}, \mathrm{TiO}_{2}$ & 0.2 & $1.0-1.5$ \\
\hline
\end{tabular}

aqueous solutions of $\mathrm{HCl}$ in order to develop a porosity and to increase the SSA. The strong acid attacks the EGF surface leaching out the non-silica components. The samples were then rinsed in distilled water and dried on air at $50^{\circ} \mathrm{C}$. The resulting porous silica enriched material was obtained in this way. The SSA of the supports was varied from 2 up to $75 \mathrm{~m}^{2} / \mathrm{g}$ by variation of pre-treatment conditions employed, like temperature and time of contact with the acidic media.

Palladium (II) chloride $\mathrm{PdCl}_{2}$ and platinum hydrochloric acid $\mathrm{H}_{2} \mathrm{PtCl}_{6}$ (purum, Fluka Chemie AG, Buchs, Switzerland) were used as precursors of the active components. The Pd and Pt supported GF catalysts were prepared by the metal deposition from aqueous $\mathrm{NH}_{3}$ solutions via well-known ion-exchange method, followed by calcination at $450^{\circ} \mathrm{C}$ on air during $3 \mathrm{~h}$. The content of $\mathrm{Pd}$ and $\mathrm{Pt}$ was varied from 0.02 to $1.0 \mathrm{wt} \%$. Before the reaction the catalysts were reduced by $10 \mathrm{wt} \%$ aqueous solution of $\mathrm{HCOONa}$ at $95^{\circ} \mathrm{C}$ during $30 \mathrm{~min}$. The main characteristics of the catalysts are presented in Table 2 .

The specific surface area of the SGF support (catalysts 1) could not be varied and was kept constant at $2 \mathrm{~m}^{2} / \mathrm{g}$. 
Table 2

The main characteristics of the GF catalysts

\begin{tabular}{|c|c|c|c|c|c|}
\hline Catalyst & $\begin{array}{l}\text { Metal content } \\
(\mathrm{wt} \%)\end{array}$ & Type of glass fibers & $\operatorname{SSA}\left(\mathrm{m}^{2} / \mathrm{g}\right)$ & $\begin{array}{l}\text { Specific pore volume, } \\
\text { SPV }\left(\mathrm{cm}^{3} / \mathrm{g}\right)\end{array}$ & $\begin{array}{l}\text { Metal surface } \\
\text { concentration } \\
\left(\mathrm{mmol} / \mathrm{m}^{2}\right)\end{array}$ \\
\hline 2. $0.2 \mathrm{Pd} / \mathrm{EGF}-15$ & 0.2 & Alumoborosilicate & 15 & $16 \times 10^{-3}$ & $1.3 \times 10^{-3}$ \\
\hline 3. $1.0 \mathrm{Pd} / \mathrm{EGF}-75$ & 1.0 & Alumoborosilicate & 75 & $48 \times 10^{-3}$ & $1.3 \times 10^{-3}$ \\
\hline 4. $0.2 \mathrm{Pt} / \mathrm{EGF}-15$ & 0.2 & Alumoborosilicate & 15 & $16 \times 10^{-3}$ & $0.6 \times 10^{-3}$ \\
\hline
\end{tabular}

The $\mathrm{Pd}$ surface concentration on this support was $10^{-3} \mathrm{mmol} / \mathrm{m}^{2}$ which corresponds to the total Pd loading of $0.02 \mathrm{wt} \%$. For the EGF supports (catalysts 2,3 ) the total content of $\mathrm{Pd}$ was varied from 0.2 to $1.0 \%$, and the supports with SSA of 15 and $75 \mathrm{~m}^{2} / \mathrm{g}$ were used to keep constant the Pd surface concentration. For the catalysts 2 and 3 the Pd surface concentration attained a constant value due the increased Pd loading proportional to the increase in SSA. In this way the influence of different parameters like SSA, the Pd surface concentration and the support chemical composition on the properties of the catalyst was evaluated.

The specific surface area, specific pore volume (SPV) and pore-size distribution (PSD) of the supports and catalyst samples were measured by $\mathrm{N}_{2}$ adsorption-desorption at $77 \mathrm{~K}$ using a Sorptomatic 1990 (Carlo Erba) instrument. For the measurements the samples were set in the ampoule in woven form. The SSA of the samples was calculated employing the BET method while the Dollimore/Heal method was applied for the calculation of mesopore-size distribution.

The investigations of surface morphology were carried out $^{1}$ via transmission electron microscope JEM-100 CX (maximum resolution of lines $2 \mathrm{~A}$, accelerating voltage $100 \mathrm{kV}$ ) and via transmission electron microscope of high-resolution JEM 2010 (maximum resolution of lines $1.4 \mathrm{~A}$, accelerating voltage $200 \mathrm{kV}$ ). We applied methods of obtaining light- and dark-field electron micrographs and of electron micro-diffraction (EMD) with up to $0.5 \mu \mathrm{m}$ localization of micro-diffraction field.

\subsection{Experimental set-up and procedure}

The benzaldehyde hydrogenation was carried out in a $100-\mathrm{ml}$ three-necked vessel operated at atmospheric pressure and at isothermal conditions ( $323 \mathrm{~K}$ ). Iso-propanol was used as a solvent. The experimental procedure was as follows: the solvent (volume $25 \mathrm{ml}$ ) with the catalyst (1-2 g) in the form of fabrics were set in the reactor in form of a horizontal layer. The solvent was stirred for

\footnotetext{
${ }^{1}$ Dr. V.I. Zaikovkii, Boreskov Institute of Catalysis, Novosibirsk, Russia.
}

30 min under continuous bubbled hydrogen flow to remove the oxygen from the reactor and to ensure a standard catalyst surface reduction. Benzaldehyde was injected in the flask via a syringe to get initial concentrations of $0.2-0.5 \mathrm{~mol} / \mathrm{l}$. The reaction mixture was continuously stirred with a magnetic stirrer and at different times about $1 \mathrm{ml}$ of the reaction solution was withdrawn by a syringe for analysis. The chemical analysis of the mixture was performed by GC Auto System XL (Perkin-Elmer) with FID. The product separation was carried out on a SUPELCO CAT No 2-5315 LOT 373504B, SPB-1, fused Silica Capillary Column $30 \mathrm{~m}$, $0.53 \mathrm{~mm}$ ID.

The initial reaction rates expressed in $\mathrm{mol}_{\mathrm{B}} \mathrm{min}^{-1}$ per gram of the catalyst $\left(R_{0}\right)$ and per gram of the metal $\left(r_{0}\right)$ were used for comparing the catalytic activities.

\section{Results and discussion}

\subsection{Catalytic activity}

The catalytic selective hydrogenation of benzaldehyde can be presented by the following scheme:

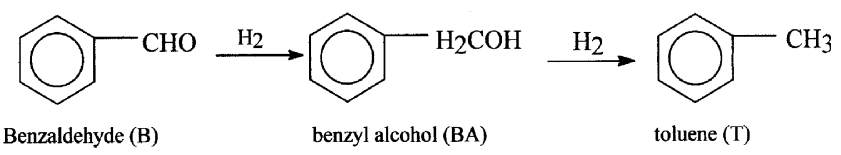

The catalysts tested showed $100 \%$ selectivity towards side-chain hydrogenation. No ring hydrogenation products were detected under reaction conditions used. Toluene is the product of the consecutive hydrogenation of benzyl alcohol. The toluene formation was observed only over Pd catalysts and always when essential part of benzaldehyde had disappeared. The typical concentration dependencies on reaction time are presented the Figs. 2 and 3 and the initial reaction rates are listed in the Table 3. Due to the high specific surface of the catalyst the volumetric mass transfer coefficient was in all experiments higher than $k_{1} a>10^{-2} \mathrm{~s}^{-1}$.

As it is seen from Table 3 the reaction rate depends on the active component used (Pt or Pd). When the same amount of metal is supported on the identical glass fiber 


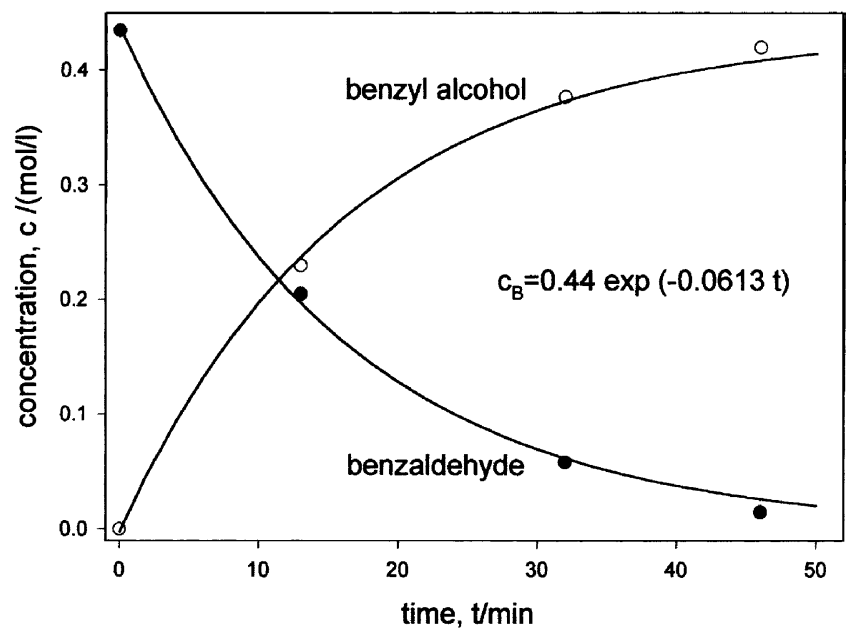

Fig. 2. Measured and predicted concentration of benzaldehyde (B) and benzyl alcohol (BA) as a function of reaction time over $0.2 \mathrm{Pt} / \mathrm{EGF}-15$ catalyst.

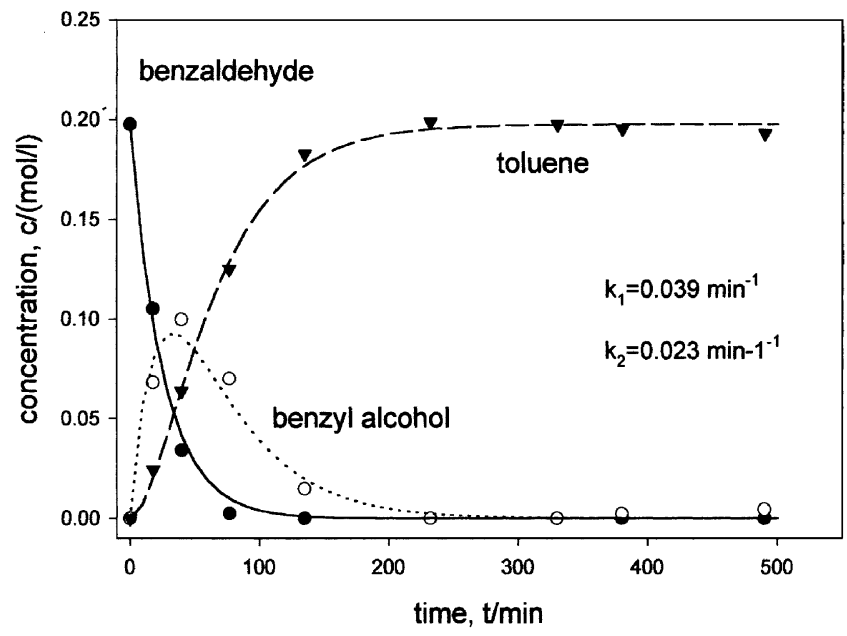

Fig. 3. Measured and predicted concentration of benzaldehyde, benzyl alcohol and toulene as function of time over $0.2 \mathrm{Pd} / \mathrm{EGF}-15$ catalyst.

material (see catalysts 2 and 4) the platinum catalysts showed two times higher activity per gram of active metal as compared to palladium. At the same time $\mathrm{Pt}$ catalysts demonstrated $100 \%$ selectivity towards benzyl alcohol formation. In all cases the specific activity per gram of noble metal $\left(r_{0}\right)$ was found to be higher compared to a standard commercial catalyst $(\mathrm{Pt} / \mathrm{C})$.

The activity of the palladium catalyst was observed to depend on the chemical composition of the support used. A catalyst with the same surface concentration of $\mathrm{Pd}$ supported on SGF (catalyst 1 in the Table 3) demonstrated a lower reaction rate per gram of $\mathrm{Pd}$ than $\mathrm{Pd}$ supported on E-type glass (see catalysts 2). This fact may be explained by strong interaction of the active component with a support. This interaction is stronger due to higher acidity of the SGF support if compared to E-type
Table 3

Comparison of activity of different catalysts in benzaldehyde hydrogenation

\begin{tabular}{lll}
\hline Catalyst & $\begin{array}{l}R_{0} \\
\left(\mathrm{mmol} \mathrm{g}_{\text {cat }}^{-1} \mathrm{~min}^{-1}\right)\end{array}$ & $\begin{array}{l}r_{0} \\
\left(\mathrm{mmol} \mathrm{g}_{\mathrm{Me}}^{-1} \mathrm{~min}^{-1}\right)\end{array}$ \\
\hline 1. $0.02 \mathrm{Pd} / \mathrm{SGF}-2$ & 0.002 & 9.75 \\
2. $0.2 \mathrm{Pd} / \mathrm{EGF}-15$ & 0.075 & 37.5 \\
3. $1.0 \mathrm{Pd} / \mathrm{EGF}-75$ & 0.675 & 33.3 \\
4. $0.2 \mathrm{Pt} / \mathrm{EGF}-15$ & 0.11 & 55.8 \\
5. $\mathrm{Pt}(5 \%) / \mathrm{C}($ commercial $)$ & 0.375 & 7.5 \\
\hline
\end{tabular}

glass. We observed a similar favorable effect of the EGF support on the catalytic activity in the gas-phase oxidation of $\mathrm{CO}$ over palladium supported glass fiber catalyst (Yuranov et al., 1999). In all experiments a first-order kinetics was observed. This confirms the results of van de Riet, Kapteijn and Moulijn (1998) who found an inhibiting effect of the benzyl alcohol resulting in a change in the apparent reaction order from zero at high benzaldehyde concentrations to one at concentrations lower than $1 \mathrm{~mol} / \mathrm{l}$.

\section{Catalyst characterization}

\section{1. $\mathrm{N}_{2}$ adsorption-desorption measurements}

In order to assess the textural properties of the catalysts the $\mathrm{N}_{2}$ adsorption-desorption isotherms at $77 \mathrm{~K}$ were determined. The specific BET surface area (SSA) and specific pore volume (SPV) were calculated from these isotherms and are listed in Table 2. We compare the adsorption-desorption isotherms of two supports with SSA values of 15 and $75 \mathrm{~m}^{2} / \mathrm{g}$. Both compounds show isotherms corresponding to type IV in the IUPAC classification (Ponec \& Bond, 1995) indicating that the materials are mesoporous. However, the observed $\mathrm{N}_{2}$ adsorption capacity is much higher for ECF-15 support $(100 \mathrm{ml} / \mathrm{g})$ compared to that of EGF-15 $(25 \mathrm{ml} / \mathrm{g})$. The lower $\mathrm{N}_{2}$ adsorption capacity of the EGF-15 can be attributed to the lower pore volume (see Table 2).

We also compared the pore size distribution (PSD) of these two supports (see Fig. 4). Both compounds show broad PSD peak in the range 15-50 $\AA$ with the maximum centered on $25-30 \AA$ pore radii. The EGF-75 exhibits a twin peak distribution of pores with the second sharp peak centered around $10 \AA$. These results are in line with those reported in literature (Zhdanov, 1955).

Based on these data obtained the process of the porosity development under acidic treatment (leaching out procedure) can be described as the appearance of broad cavities on the surface followed by well-defined deep pores inside the fiber network. 


\subsection{Electronic microscopy}

One of the objectives of this work was to study the morphology of the support surface and its influence on the active metal dispersion and the catalytic activity. For this purpose, high-resolution transmission electronic microscopy (HRTEM) investigation of the catalysts was carried out after different reductive treatment. The precious metal interaction with the support involves the active metal dispersion, sintering and reduction. In this study we compared Pd properties of the same concentration per surface unit of SGF and EGF supports.

From the TEM observations it follows that for the both supports SGF and EGF types a high dispersion of Pd was obtained for the catalysts reduced by sodium formate solution. As seen from the Fig. 5a the small particles with diameter 10-30 ̊ predominate, although some bigger particles were also observed. The HRTEM images allowed to obtain the crystallographic para-

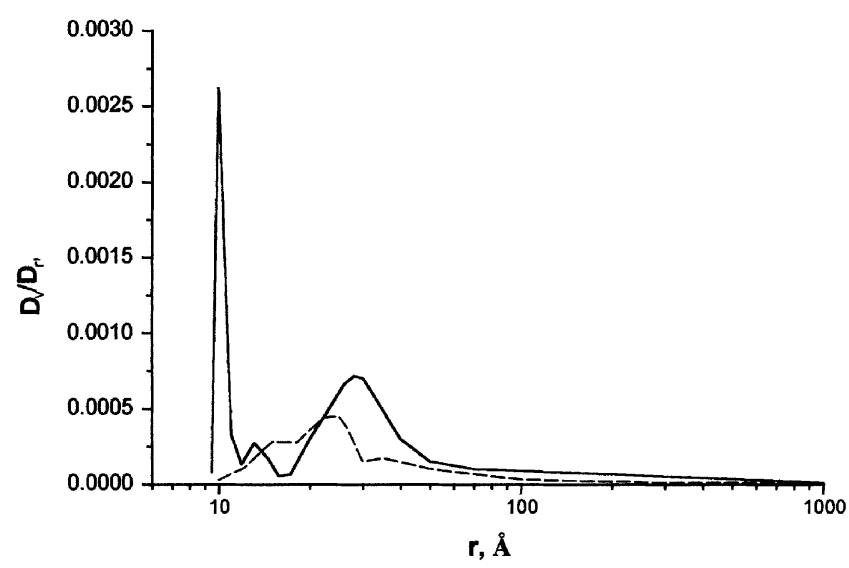

Fig. 4. Pore size distribution curves; (solid line EGF-75; dotted line EGF-15). meters of these particles by direct measurements of the distances between the plane projections (see Fig. 5b). The values of 2.25 and $1.95 \AA$ correspond to (111) and (200) crystallographic planes of metallic Pd (X-ray Powder Data File, 1996).

\section{Characteristics of the structure of GF catalytic bed}

The main design parameters of the glass fiber catalytic bed are presented in Fig. 6. The threads of the fabrics consist of 50-100 filaments with a diameter $d$ of 3-15 $\mu \mathrm{m}$ twisted to bundles with a diameter $D$ of several hundred microns. The equivalent diameter of the macropores inside the thread is defined by the diameter of the elementary filaments and is in the order of several microns. Therefore, the transport limitations inside the bundles will not take place of reactions with characteristic reaction times more than $10^{-2} \mathrm{~s}$.

Among the most important characteristics of the structured catalytic packed bed are the pressure drop and the static liquid holdup. The values of these parameters depend on the overall void fraction of the bed $\left(\varepsilon_{\text {bed }}\right)$ defined as the volume of the liquid phase with the catalytic bed referred to the total volume of the empty reactor. Besides of the thread diameter the $\varepsilon_{\text {bed }}$ value depends on the width $(w)$ between the threads and the distance between the layers $(b)$. These design parameters can be varied in a wide range and optimized for the specific reaction conditions. In particular, the continuous phase (liquid or gas) will strongly influence the final design of the catalytic bed. For example, if the liquid phase is the continuous one, like in the case of the packed bubble column, the catalytic bed should be organized as parallel superior posed layers perpendicularly to the liquid flow. For a trickle-bed reactor with gas as a continuous phase a vertical position of a rolled GF layers should be a
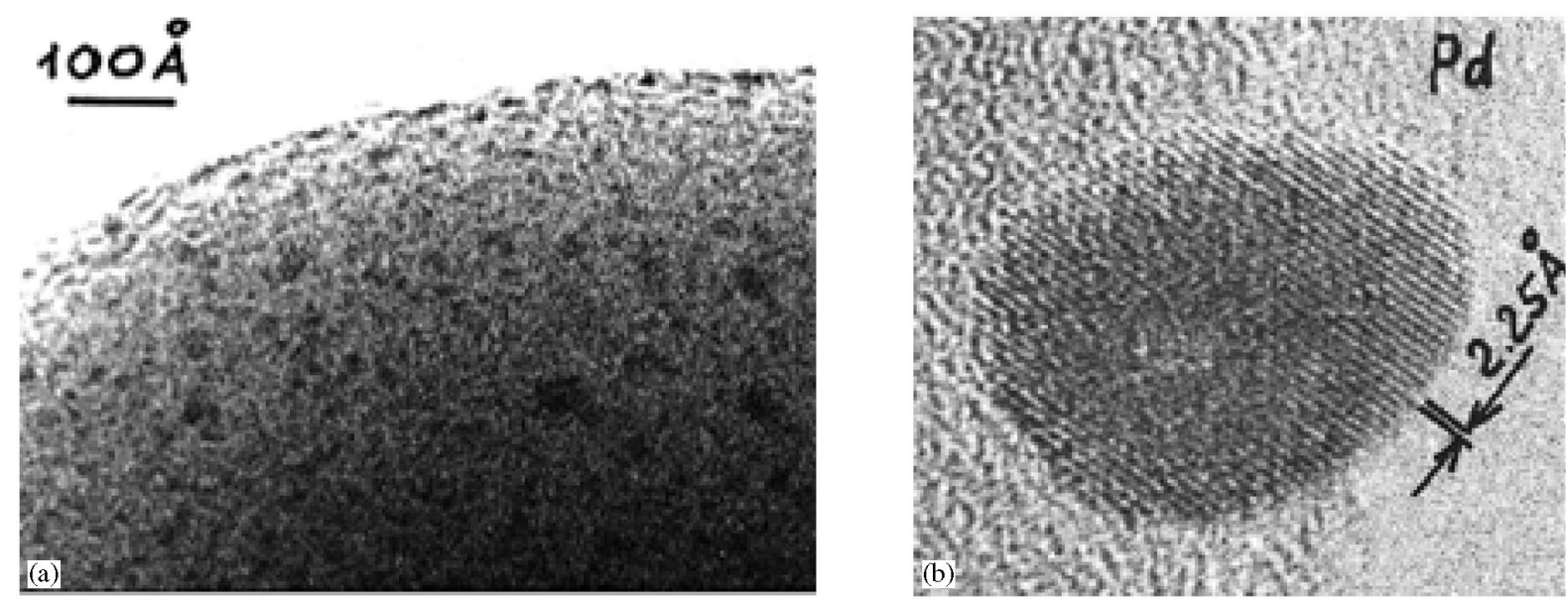

Fig. 5. TEM image of $0.2 \mathrm{Pd} / \mathrm{EGF}$ catalyst after reduction at $95^{\circ} \mathrm{C}$ by sodium formate solution. (a) the overall view of Pd metal particles distributed on a glass fiber surface; (b) high resolution TEM image of one Pd particle, which is a single crystal, showing (111) lattice fringes $0.22 \mathrm{~nm}$. 


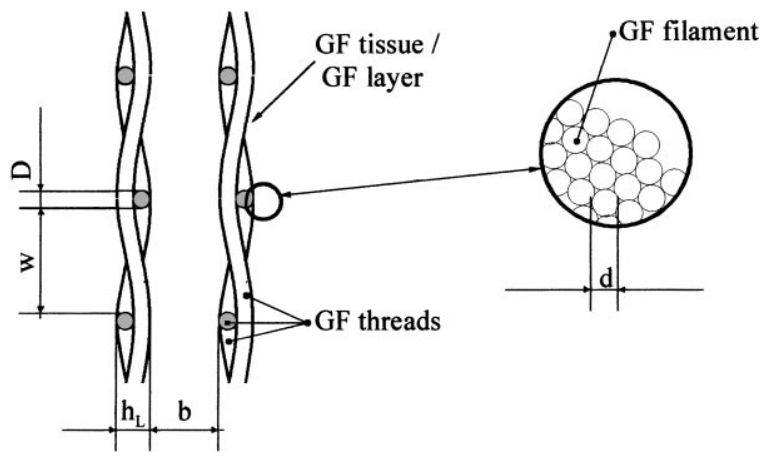

Fig. 6. Scheme of a GF catalyst structure.

favorable design. In this case liquid can trickle along the layers from the top to the bottom of the column.

\section{Acknowledgements}

The financial support provided for this work by the Swiss National Science Foundation is gratefully acknowledged.
The authors also would like to thank Prof. V. Barelko for fruitful discussions and Dr. V. Zaikovskii for high expertise of EM measurements.

\section{References}

Barelko, V., Dorohov, V., Private communication.

Irandoust, S., Cybulski, A., \& Moulijn, J. (1998). Structured catalysts and reactors. In A. Cybulski, \& J. Moulijn, Chemical industry, vol. 71, (p. 239)

Neyestanaki, A. K., \& Lindfors, L. -E. (1995). Combustion Science and Technology, 110-111, 303.

Nicholas, D. M., Shah, Y. T., \& Zlochower, I. A. (1976). Industrial Chemistry Product Research and Development, 15, 29.

Ponec, V., \& Bond, G. C. (1995). Catalysis by metals and alloys. In Studies in Surface science and catalysis, vol. 95. Amsterdam: Elsevier.

van de Riet, A. C. J. M., Kapteijn, F., \& Moulijn, J. A. (1998). Second international symposium catalysis in multiphase reactors, Toulouse (pp. 153-159).

X-ray Powder Data file, Set 46, $\mathrm{N}^{\circ} 1043, \mathrm{~N}^{\circ} 1107$ (1996). JCPDF International Center for Diffraction Data, PA, USA.

Yuranov, I., Kiwi-Minsker, L., Barelko, V., \& Renken, A. (1999). Studies in Surface Science and Catalysis, 122, 191-198.

Zhdanov, S. P. (1955). Structure of glass. New York: Consultants Bureau. 